\title{
SOCIAL EQUITY IN FARMER-MANAGED IRRIGATION IN THE TERAI OF NEPAL
}

Laya Prasad Uprety

\section{Prelude}

This paper aims to ascertain and explicate the role of 'social equity' in the sustainable management of water for irrigation as a 'common property resource' by focusing on two farmer-managed irrigation systems from the western Terai. It begins with a brief analysis on the theoretical understanding of water for irrigation as a 'common property resource' and 'social equity' and offers specific in-depth empirical understanding and explication on the role of 'social equity' in the sustainable irrigation management.

\section{Understanding Water for Irrigation as a Common Property}

\section{Resource}

It is contextual to have a brief understanding on the very notion of 'common property resource' before gaining clarity on the understanding of 'water as a common property resource' wherein 'social equity' variable plays an important role for the sustainable irrigation management and development.

\section{Understanding Common Property Resource (CPR):}

The literature on CPR basically focuses on the organizational and institutional arrangements for the management of a particular resource, which is traditionally conserved and exploited by a group 
of people for their livelihood. Only the co-owners who have contributed to conserve, develop and sustain the resource for their livelihood over time do have the property right on it, and can use it with full sense of security. And they can also transfer the ownership of the resource as property to other potential resource appropriators. Thus, following Place and Shallow (2002), I would argue that exclusivity, security and transferability are the main characteristics of common property resource management, which are largely governed by the institutions. Jodha (1974) asserts that common property resources are the resources accessible to the whole of the community of a village and to which no individual has exclusive property right.

According to Bennett (1996), common property means that the group has a collective responsibility for resources, which tends to guarantee care and conservation; Some of the common elements regarded as crucial common property resource include a collective sense of responsibility for resources, sharing of resources by a specified group of people with specified rights and controlling of such resources by an identifiable groups (see Bennett 1996; Fisher 1991; Berkes and Farvar; 1989). They also note that common property systems are characterized by the presence of arrangements for allocation of the resource among co-owners. They provide mechanisms for the equitable use of the resources with a minimum of internal strife. They are the integral part of the local culture.

Ostrom (1997) and Ghate (2003) hold the opinion that the selfinitiated efforts for the management of common property create a condition for the resource users to be involved over time in making and adopting rules within collective choice arenas regarding the inclusion or exclusion of participants, appropriation strategies, obligation of the participants, monitoring and sanctioning, and conflict resolution. A shared understanding of social norms plays a crucial role in community-initiated management regimes. Collective action for resource management through organizational efforts comes into being as the function of resource scarcity. The co-owners of a resource have, in fact, crated the indigenous institutions for the governance of the behavior of the resource appropriators from which a lot of social learnings can be borrowed to feed in the contemporary mainstream development model.

\section{Understanding Water as a Common Property Resource}

Co-operative relationship for the exploitation and utilization of water for irrigation by sharing is the function of the transient nature of water. Martin (1986) regards water resource as a "fugitive" natural resource. "Fugitive" resources are mobile and must be captured before they can be allocated to individuals or groups. Since such capture and allocation poses the problem of exclusion, institutional regulation of these resources tends to develop early. Referring to the work of Ciriacy-Wantrup and Bishop (1975), Martin (1986) argues that common property institutions are the most important means of regulation of "fugitive" resources." $\mathrm{He}$ considers a farmer irrigation organization as the owner and manager of water as a common property. He (1986:231) writes:

The rights to the water in the source are vested in the group. Irrigation organizations work vigorously to exclude nonmembers from using the water. The amount of water that members can use and when they receive it is regulated by the organization.

Coward (1986) views irrigation development as a property creating or a property-reproducing process. Collective action is based on property relations because irrigation groups formulate principles of action and perform irrigation tasks that reflect prior and continuing investments in their hydraulic property. He considers this 
relationship of co-property holders as the factor legitimizing and activating their solidarity.

P. Pradhan (1989) treats water as community property: an organizing force for farmers in a given system. In a well-organized system, the beneficiaries perform irrigation-related tasks collectively or the individuals carry out group agreements. He argues that the concept of "community property" has become the basis for organization in all sectors as well. Once the resource becomes the community property, the group must organize to preserve it and distribute the benefits to members of the community. This, he argue, requires a viable community-based organization. Protection of the water rights is an organizing force (e.g. guarding the source of water at night in group on rotational basis). Similarly, achieving water distribution in proportion to water share is also an organizing force (water shares are distributed among the members on the basis of investment made during the time of construction and in some cases, water shares are distributed in proportion to the area irrigated). Organizations are designed for the acquisition of water, mobilization of manpower and local resources to operate and maintain the system, equitable water distribution and minimizing conflict.

Coward presents the conceptualization of the sociology of irrigation in the regime of common property. He argues that a sociological perspective of irrigation can commence with two fundamental concepts, namely, 'institutions' and 'social organization'. He (1985: 30) writes:

"Institution" in irrigation refers to ideal behavior and role expectations and as a generic concept for the variety of rules that help pattern social behavior: norms, folkways, mores, customs, convention, etiquette, and law. ... In addition to these institutions, there are in any human group patterns of social behavior and interaction that are referred to as the social organization.

Discussing the principles of irrigation organization for managing water as a common property, Coward (1979) in another context states that the operation of an irrigation system is a complex organizational enterprise that involves engineering and construction activities, the management of soil- water relationship, the allocation of water rights to groups and individuals, and other activities. While there are many tasks which must be organized to sustain the operation of an irrigation system, three are of fundamental importance: (i) the organization of water allocation; (ii) physical maintenance activities; and (iii) conflict management.

Norman Uphoff (1986) also holds the notion that four basic sets of activities-decision-making and planning, resource mobilization and management, communication and coordination and conflict resolution-constitute the core of an organization for managing the water as a common property resource.

Ostrom (1992) has developed the "institutional design principles" of long-enduring self-organized irrigation systems on the basis of empirical evidences. For her, a design principle is an element or condition that helps to account for the success of institutions in sustaining the physical works and gaining the compliance of generations of users to rules-in-use. She presents the design principles that characterize long-enduring, self-organized irrigation institutions. These comprise: the clearly defined boundaries of the service area and the individuals or households with rights to use, proportional equivalence between benefits and costs; collectivechoice arrangements; monitoring; graduated sanctions; conflict resolution mechanisms; minimal recognition of rights to organize and nested enterprises She discusses institutions as rules-in- use. 
Thus, there has been the emphasis on the forms of structural social capitals and their roles in sustaining the irrigation management. In other words, the irrigation collective actions are governed by the set of cultural norms collectively developed and complied with by the irrigators for their mutual benefits and in so doing, the role of the irrigation organization is crucially important for acquiring the water in the canal from its source, mobilizing the resources for the regular repair and maintenance of the canal, allocating and distributing the water equitably among the irrigators, and managing the conflicts.

\section{Understanding Social Equity in the Context of Sustainable Common Property Resource Management}

The term 'social equity' has acquired much currency in the contemporary literature of development. The scholars working in people-centered sustainable development have scrupulously underscored the notion of "social equity". The existing social science literature on developmental practices describes "social equity" as "social justice in benefit sharing" or the "fair distribution of benefits". In this regard, Korten (1990: 4) succinctly writes:

Justice does not require equality of income, nor does it require that the productive be required to support the slothful. It does require, however, that all people have the means and the opportunities to produce a minimum decent livelihood for themselves and their families.

Other development scholars working in the regime of common property resource management (Gilmour and Fisher 1992; Mukherjee 2001 and Carol et.al 2002) have also emphasized on the say or the active participation of the members of various interest groups. Pointing out the importance of a fairly broad-base ambience for decision-making to represent the interests of all groups utilizing a particular common property resource, Gilmour and Fisher (1992) underscore to ensure the meeting of the legitimate interests and needs of disadvantaged groups and empowering them to enhance their effective role in decision-making. While dealing with the ingredients of the social equity, Carol et.al (2001) have underscored the sufficiency of access to resources; economic opportunity, decision-making opportunity and justice. Mukherjee (2001) is very much concerned with the equitable distribution of benefits from the group-based activities for the management of common property resources. For him, the criteria considered for reflecting 'equity' in measurement of social capital are broad-based understanding of group activities and worldview, group participation in decisionmaking, equity in benefit-flows and livelihood impacts and reduction in vulnerabilities.

Thus, there has been an increasing emphasis on the notion of 'social equity' or 'distributive justice' as one of the guiding principles of contemporary people-centered development paradigm. Policymakers have been asked by the development professionals and researchers as well as the communities themselves to make the optimal efforts for ensuring sustainable access to common property resources. Carol et.al (2001) underscore that such an access implies three qualities: that the resource remains in sufficient quantity and quality; that the people can use it as needed or to the same extent as in the past, and that 'fairness' or 'equity' exists in regulations governing its use and distribution. Gautam and Uprety (2002) have argued that the development of water resource as a common property has to be geared towards promoting equity by simultaneously underscoring the institutional inclusiveness through the representation of the potential beneficiaries in the decision-making and implementation and accountability of the different stakeholders involved in the development process.

On the basis of theories of social psychology Lind (1995) treats fairness or social equity or justice as a device for resolving conflict. Discussing the fairness norm, he states 
that people are generally willing to accept compromise, as long as outcomes are fairly distributed and as long as the clash of people, groups and ideas is governed by rules that are just and evenhanded. He also notes that people are willing much of the time to subordinate their own desires to the greater good, as long as they have faith in some fundamental fairness in the way that greater good is achieved.

Slater and Chasca (2003) have also underscored the need to understand the place of equity or social justice with the livelihood systems because by exploring it, the sensitivity of our understandings can be enhanced and links between incentives, actions and institutions developed. This involves exploring rights-based approaches to natural resource use and management and the links to livelihoods. They also argue that our understanding of equity and justice relates very closely to notions of rules and practices. We need a more sophisticated understanding of the structure of rights that can address the questions of justice and that these are desirable goals. Participation of the broader community in the management of the resource, fair decentralization of decision-making, and fair distribution of benefits can regulate the "free-riding".

Pradhan (2001) is of the opinion that equity of distribution does not mean equal distribution to all, but distribution according to a system of rules, which everyone can understand. Sometimes, rules allow different groups to receive quite different quantities of water, but users accept the fact because they know the basis for the rules. He underscores that the rule system must be transparent, easy to understand, operate, and monitor.

Some other scholars working in the regime of water for irrigation have also focused on equity in resource mobilization and irrigation access (see Shukla and Sharma 1997; Tang 1989). From the foregoing discussion it becomes clear that most scholars agree that resource management systems which have emphasized participation of the various interest groups in the governance structures and decision-making processes in the most inclusionary way, and equity in the resource mobilization and distribution of the benefits have remained sustainable.

\section{The Social Settings of the Study Area}

Research was conducted in the command areas of Sora and Chattis Mauja farmer-managed irrigation systems located in the plains of Rupendehi district. These irrigation systems have a command areas of about 1,500 and 3,500 hectares of land, respectively. These were originally constructed by the autochthonous Tharu people of the Tearai. Initially, the Sora Mauja irrigation system served a total of 16 Maujas (settlement areas which roughly corresponded to villages) and Chattis Mauja irrigation system served a total 36 Maujas. But the command areas of both the systems later expanded a function of the population growth triggered by the Hill to Terai migration particularly after 1960 . The migrants comprise Brahmins, Chhettris, traditional service caste people and indigenous nationalities of Mongoloid origin.

Field research in 2003 revealed that, the Sora Mauja was expanded to 30 Maujas and Chhattis Mauja was expanded to 56 Maujas. The increase and decrease of the number of command Maujas depends on whether the farmers make the regular collective contribution of labor and financial resources for the repair and maintenance of the irrigation systems. Though both these systems were originally developed in two different locations of Tianu River more than 170 years ago, they have been sharing water from a single mega- canal since 1964 . Since then, the mega-canal has been jointly managed up to the point of bifurcation (called Tara Prasad Bhond) from where water has been divided between the two systems proportionate to the size of their respective command areas. 
Despite the heterogeneity in the social structure of the beneficiary farmers of the command areas, both irrigation systems have been effectively functioning for a relatively long period and have become the often-cited references of the participatory and sustainable irrigation systems in Nepal. Hence, I have selected these two systems to document the role of social equity among the stakeholders of irrigation systems with a view to generating the social learnings, which are worth sharing for the wider academic discourse on developmentalism (i.e external intervention vs indigenous model or the blending of the both?) for the sustainability of the development, including in the regime of water as a common property resource.

\section{Methodology Employed}

The fieldwork for garnering the data to write this paper was conducted in March and April of 2003. While drawing the sample locations for the study, first of all, the whole command area of both irrigation systems was divided into head, middle and tail locations in consultation with the key informants. And one Mauja was randomly selected from each location of the Sora Mauja irrigation system, which is a total of three Maujas (10\% of the total 30 Maujas during the period of the study). Similarly, two Maujas were selected from each location of Chattis Maujas, which is a total of six Maujas (10.7\% of the 56 total Maujas during the period of the study).

A total of 31 key informants were selected and interviewed to obtain qualitative information. Of these, four comprised from the joint management committee (the chairman, vice-chairman, secretary and Meth Muktiyar - chief staff), 11 from Sora-Mauja (the chairman, vice-chairman and secretary of the main committee, two Meth Muktiyars- chief staffs, three Mauja Muktiyars-village level staffs, and three regional representatives out of the six) and 16 from
Chhattis Mauja (the chairman, vice-chairman and secretary of the main committee, Meth Muktiyar-- chief system level staff, six regional representatives out of nine, and six Mauja Muktiyars-village chief staffs) from six sample village-level irrigation committees. They furnished data on the role of social equity among the stakeholders of both the systems and their role in the sustainability of the irrigation management.

The primary data was collected by means of the ethnographic method, Ethnographic method in this research involved the direct and participant observation and key informant interviews. Utmost effort was made for the triangulation of the information generated in the field.

\section{Social Equity Regime in Sora and Chattis Mauja}

This section focuses on the governance structures for ensuring the social equity in a multi-stakeholder situation through the involvement of various interest groups. In particular it deals with decision-making processes as well as equity in resource mobilization and management, distribution of water for irrigation, and information sharing. Rules for conflict management and for maintaining the transparency and accountability for ensuring the equity/fairness are also discussed.

\section{Governance Structures in a Multi-stakeholder Situation}

It is contextual to have the understanding on the notion of 'governance' in farmer-managed irrigation system (FMIS) before explicating the empirical facts. Coward (2004) shares that FMIS needs to govern the internal actions through the exercise of authority or control and management such as building and repairing water works, allocating and distributing water and resolving conflicts and disagreements among water appropriators. He also 
underscores the external activities to be organized including dealing with other irrigation groups and state and its agencies. Governance is also concerned with organizing group actions to deal with the vagaries of the environment. In fact, non-state entities such as the irrigation organizations govern the behavior of the water appropriators in the management and the utilization of water for sustained irrigation. Thus, FMIS governance is vitally important for the effective and continuing operation.

Both the irrigation systems under study have the nested enterprises of the governance organizational structures. They have threelayered of the governance-nested enterprises, namely, system level executive committees, regional committee structures, and Mauja level committees. Put in other words, they have the federated governance structures. Given the fact that both systems have shared the water from the single mega- canal, they have also formed a Sora-Chhattis joint management committee comprising the representatives from both the irrigation systems.

Given the fact that the Sora and Chhattis Mauja started to share water from the same diversion since 1964, the water management effort became joint from the headwork to Tara Prasad Bhond-- the place from where the water has been bifurcated/divided proportionate to the size of their respective command areas. And all this was feasible only through the formation of a joint governance structure comprising the representatives from both the systems. Both the systems have the constitutional provisions to send representatives to it so long as the committee has the justification of being in the operation. As per the understanding of the representatives of the two systems, Chhattis Mauja nominates six members and Sora Mauja nominates five members from their respective system level executive committees making a total of 11 members. Of the 11 members, one is elected as the chairman, one vice-

chairman, one secretary and one treasurer as the functionaries and other remain as the members. The committee has also Meth Muktiyar (chief staff) and one Chaukidar (watchman-cummessenger).

Both the systems have provisions of appointing Meth Mukthiyars (chief system level staff-one in Chhattis and two in Sora) and other staffs for discharging the irrigation-related activities with the direction of the executive committees. Both have the provision of the appointment of organizationally and institutionally speaking, they are the backbones of both the systems because in actuality, they are the ones who play the instrumental role in making the systems operational by mobilizing the Kularas in the Kulahai (labor contribution for repair and maintenance) and distributing water between and among the Maujas equitably as per the direction of the executive committees. They are basically assisted by the Chaukidars (watchmen) in discharging their duties.

In the case of both irrigation systems, there is also the provision of Mauja Muktiyars (village level staffs) who are selected by the water appropriators of the particular Mauja (village) and are responsible for disseminating the information of the village level committee apropos of its activities, distributing water equitably, mobilizing the labor, resolving the conflicts, getting the decisions of the executive committees implemented, etc. Though not universal, there is also the Gaun Chaukidar (village level watchman) in the irrigation systems who comply with the orders of the Gaun Muktiyars, Chetradakshya (regional chairman/representative) and executive committee. He plays the crucial role in the exchange and dissemination of the information.

Both Sora and Chhattis Mauja irrigation systems have their democratic culture in the regime of decision-making. At the Mauja level, all the water appropriators have the opportunity to have their 
say during the time of Mauja level general assemblies or any other mass meetings. Their genuine voices, regardless of the caste/ethnic and class statuses, are heard by the concerned functionaries and staff and decisions made accordingly. If any genuine problem related to the irrigation, resource mobilization and any other related works crops up during the discussion of the general assemblies, decisions are made immediately in a participatory way. If it can be resolved at the Mauja level, the functionaries of the Mauja level committee and the Mauja Muktiyar make efforts for this. But if it cannot be resolved at this organizational level, this is communicated to the higher-level committees and staff of the organizations. In both the irrigation systems, the regional level committee structure composed of the representatives of each command Mauja simply works as the link between the system level executive committees and Mauja level committees.

The Amsabha (the general meeting) and the Sadharansabha (general assembly) are also the powerful bodies for making the decisions where the representatives of the farmers from all the Maujas participate. In these fora, every representative has the opportunity to articulate clearly the inter-systemic, systemic, interMauja and intra-Mauja (which cannot be solved locally) irrigationrelated problems and actively contribute to the process of decisionmaking and planning. During the process of decision-making, majority view is granted. It is the same case in the Sora-Chhattis Mauja joint committee.

In both the irrigation systems, the planning approach is highly decentralized. More specifically, the planning for the jointlyoperated canal up to Tara Prasad Bhond is the domain of the SoraChhattis joint management committee. The system level planning is the domain of the autonomous executive committees. And finally, the Mauja level planning is the domain of the Mauja level committee. The planning activities have to happen within the boundary of the constitutional arrangement and the annual policy level decisions made by the general meetings/general assemblies.

In the governance-nested enterprises of both the systems, the resolutions are passed either through consensus or voting system. Each organizational nested enterprise formulates its plan every year for the water acquisition, system maintenance, water distribution, and resource mobilization with emphasis on social equity.

\section{Equity in Resource Mobilization and Management}

The water appropriators of both the systems have developed an organizational culture for mobilizing and managing the resources/ inputs required for the repair and maintenance and operation of the irrigation systems in the most equitable fashion. In fact, the operational rule implemented by the elected functionaries and employed staffs with the mandate of the water appropriators has been immensely instrumental in sustaining the irrigation systems. In fact, it is this aspect of culture that has the bearing on the popularization of these two relatively old irrigation systems. This relative strength has enticed a large number of the lead farmers and trainees from other parts of Nepal to visit them for learning about the resource mobilization and management culture.

In both the systems, the principal financial sources include: (i) Khara Sulka (fines) collected in the case of the non-contribution of the labor by the water appropriators; (ii) fines collected from the persons/Maujas who have violated the rotational rule of the water distribution or stolen water in others' turn; (iii) fee collected while changing the Mohada (diversion location) of the branch canals from the system main canal; (iv) entry fee for any new Mauja and reentry fee for old Mauja (who relinquished to use water after using for some time) charged on the basis of the number of Khetala 
(laborer) to be made available for the annual repair and maintenance of main system canals; (v) money collected from the water appropriators during the time of emergency (in the form of the assistance); (vi) any amount of money received from government, non-governmental organizations and persons in form of grant, etc, and (vii) Bigathhi (the annual irrigation service fee rate to be paid to the organization if one is unwilling or not available to contribute the labor for the system repair and maintenance and the rate varies from one Mauja to the other).

The basis of labor mobilization for the repair and maintenance of the headwork and jointly-operated section of the mega- canal system is Kulara in both the systems. One Kulara means one laborer per 25 Bighas of land. Both the systems have a typology of Sheer Kulahai (labor work for the repair and maintenance of the headwork of the canal). These are called Sabik (one laborer per 25 Bighas of land per day), Double (two laborers per 25 Bighas of land per day), Treble (three laborers per 25 Bighas per day) and Chauble (four laborers per 25 Bighas of land per day). Generally, Sabik system of labor mobilization is practiced if the repair and maintenance work is not voluminous. The increase of the number of the laborers is the function of the volume of the siltation and the debris along the alignment of the head of the main canal. When there is tremendous amount of work for desilting the headwork, there may be the exhortation from the executive committees of both the systems for sending one laborer from each household compulsorily, which is called Jharuwa in the local parlance. Thus, labor for the Sheer Kulahai is generally mobilized in the equitable way. The Meth Muktiyar of the Sora-Chhattis joint management committee mobilizes the laborers for Sheer Kulahai with the regular co-operation of the Meth Muktiyars of Sora and Chhattis Mauja systems who are remunerated for their services.
The Meth Mukthiyars of both the irrigation systems also play the instrumental role in mobilizing the labor from each Mauja for the repair and maintenance of the separate Sora and Chhattis canal systems. Both the systems have a traditional norm of assigning the Maujani Naj (in the parlance of Sora-Mauja) or Maujani Nath (in the parlance of Chhattis Mauja) which is the measured area of the main canal assigned to a particular Mauja for its annual repair and maintenance. It is always the responsibility of the individual Mauja to clean the canal portion assigned to it either on the basis of the labor mobilization of the irrigator household proportionate to the size of the landholding or on Jharauwa basis in isolated cases. Labor contribution proportionate to the size of the holdings is more or less universal in both the systems.

Both the systems have developed a norm to pay Khara for failing to contribute the labor to repair and maintain the canal systems. The potential punishment is determined by the responses of the concerned Mauja. If the punishment is also ignored, the noncomplaint Maujas may face the dismissal. Both the systems also have developed the norm to repair and maintain the branches, tertiaries, water courses and field channels with the labor/cash contribution from the beneficiaries of the command area.

The governance structures of both the systems have been extremely successful in the mobilization of the internal resources. They are maintained by the internal resources. Put in other words, the payment of the remuneration of the staff and operation cost is largely met by the amount of Kharas collected every year. In exceptional cases, there is also the exemption. For instance, in Sora-Mauja, if there is any genuine cause for not paying the amount required and labor demanded, the Mauja can be exempted. The Meth Muktiyar needs to consult the chairman of the executive committee and follow his directive. 
Though land ownership or leasing -in the land within the command area, membership in the organization, payment of certain entry fee each time before withdrawing water and regular contribution of labor or cash or both for the repair and maintenance of the irrigation system create the bases for the creation of the property rights for a particular water appropriating household, each household of SoraMauja and Chhattis Mauja has to contribute labor or Bighatti (irrigation fee per Bigha) every year for the irrigation system maintenance. Failure to do so results in the deprivation of the water rights. And all this is indicative of the fact that there is complete control of the free-riding behavior which has, in turn, generally contributed to ensuring equity in labor or cash resource contribution for the operation and maintenance of the irrigation systems.

Though resource contribution is generally proportionate to the size of the land holding, there are isolated instances of mobilizing the labor on "Jharuwa" basis (compulsory contribution of labor every day until the repair and maintenance is over). The raison d'etre of the continuity of the practice of the Kulara system is that it is the most equitable system of labor mobilization for the repair and maintenance of the headwork and the jointly-operated canal system, which ensures water rights for the farmers without any form of exploitation. The system was the function of the abandonment of the Jharuwa, Sidhabandhi (labor contribution with foodstuff for the night halt until the repair and maintenance is over) and Bhujabandi (labor contribution with tiffin to work for the full day until the repair and maintenance is over) systems practiced in the past which was exploitative in nature (because the small holders had to contribute same amount of labor like the large holders). Nonetheless, there is still the remnant of Jharuwa system to a lesser extent among a few Maujas for the Mauja level repair and maintenance and large-scale emergency maintenance of the headwork of the common mega- canal.

\section{Equity in Water Allocation and Distribution}

Albeit the terms "allocation" and "distribution" are interchangeably used, they have different connotations in the literature of irrigation. "Allocation" is the entitlement to the use of water, which is mutually agreed by the beneficiaries and "distribution" is the actual delivery of water to their fields as per the agreed principle. A permanent proportioning divider has been constructed at a place called Tara Prasad Bhond as per the consensual decision between the representatives of both the systems. The total volume of the water running in the single mega-canal has been considered to be 16 annas (a local unit of measurement for 100\%) of which 6.5 annas of water has been allocated to Sora-Mauja and 9.5 annas of water was allocated to Chhattis Mauja. The permanent structure is such that automatically divides the flowing water in the two separate canals as per the agreed principle, which ensures equity in the actual distribution of water between the two systems.

In both the irrigation systems, the water appropriators have evolved their own cultural norm of water allocation, that is, Kulara is the basic water allocation unit. As indicated above, the traditional local cultural definition of one Kulara is the 25 Bighas of land. Each Mauja is required to send one laborer for the repair and maintenance of the main system canals per Kulara as and when needed. Thus, traditionally, each Mauja has the right to claim the fraction of the total discharge of water perennially flowing in the main canals, which has to be proportionate to the number of the Kularas. Kulara has still been the unit of labor/cash contribution or resource mobilization. Kulara has been found easier unit for them to calculate the share of water and resource contribution from the water appropriating Maujas. This has been primarily so because one can claim the right to water upon the fulfillment of the requirement of resource contribution (cash or labor or both). 
The general practice of the water distribution from the outlets of the main canals depends on the number of Kularas assigned to a particular Mauja. In both the systems, water flows continuously in all the branches during the period of the abundance of water in the rainy season. And particularly for the water scarce period in winter and spring seasons, the water appropriators have evolved an operational cultural norm of the rotational distribution of water. The system level executive committees decide the number of hours for the rotational distribution of water. For instance, in the case of Sora Mauja, one Kulara may get 8 hours' water distribution per Kulara. It was reported that water is distributed for 6-7 hours per Kulara in Chhattis Maujas by preparing water schedule.

In both the systems, the outlets for the branch canal for water distribution from the main canals are constructed as per the decision of the system level executive committees. Though the outlets are manually constructed based on the observational judgment, they are reliable to distribute the water as per the allocation principle. The outlet of Mauja is measured as per the availability of water in the main canals. The width, length and height of the outlets are determined on the basis of the number of Kularas (despite the fact that they do not have the scientific system of measurement and control). Sacks of sand are used to control the outlets of water from the main canals.

Once the water flows within the boundary of the Maujas in both the systems, the Mauja Muktiyars, with the advice of the Mauja level committee and the assistance of the Mauja Chaukidars, distribute the water by preparing the water schedule for the head, middle and tail locations within the Mauja settings regardless of the abundance and scarcity of the water. In practice, the Mauja Muktiyars and Chaukidars monitor the effective execution of the rotational distribution of water. As indicated above, during the water scarce period, water appropriators within the Maujas strictly follow "Ghante Pallo" (hourly turn). At the Mauja level, each household gets water to its field proportionate to its size. The effective internal resource mobilization is possible because of the equitable distribution of water to grow crops.

\section{Equity in Information Sharing}

The existence of in-built cultural norm for the communication within the organizations of the irrigation systems and between the irrigation organizations of the two systems and other external agencies and between and among the water appropriators is of paramount importance. Both irrigation systems have also developed their own reliable systems of communication. Within the systems, the decisions made by the executive committees about the resource mobilization for the systemic regular and emergency maintenance and water allocation and distribution are communicated to the Mauja level committees and Mauja Muktiyars by the Meth Muktiyars with the support of the Chaukidars/office assistants of the executive committees. Once this is done, the Mauja Muktiyar, with the support of the Mauja Chaukidar, disseminates the information among the water appropriators of the Mauja. Occasionally, the water appropriators also meet the system level Meth Muktiyars and functionaries/members of the executive committees. During such meetings, the water appropriators are also informed informally about the organizational decisions and the irrigation-related activities. During the period of the general meetings/general assemblies in both the systems, the representatives of the water appropriators participate in the decision-making process and during that time also, they communicate the operational problems of command area Maujas faced by the water appropriators. This is one way of the communication from top to bottom. 
But there is also the system of bottom-up communication. For example, the decisions made by the Mauja level committee are communicated to the Meth Muktiyars or the functionaries of the executive committees through the Mauja level chairmen/ Muktiyars / Chaukidars. The complaints lodged by the water appropriators at the Mauja level (if they cannot be solved locally) are also communicated to the executive committees/ Meth Muktiyars in the same way. The nine regional representatives of Chhattis Mauja and six regional representatives of Sora Mauja also work as the link of communication between the Mauja level committees and executive committees. If there is any serious operational problem being confronted at the Mauja level by the water appropriators, they communicate it to the Mauja level committees /Mauja Muktiyars who send message to the system level executive committees/Meth Muktiyars for their support to resolve it.

The decisions made by the executive committees that potentially affect both Sora and Chhattis are also communicated to the joint management committee and its Meth Muktiyar through the Chaukidars or Meth Muktiyars or other functionaries of the executive committees who represent the system in the joint management committee. Depending upon the gravity of the problem/issue, both formal (through written letters) and informal (oral) means of communication are used. The Meth Muktiyar/ the secretary of the joint management committee communicates the message to the Meth Muktiyars of the Sora-Chhattis Maujas through its Chaukidar and their system level executive committees on the regular and emergency maintenance work and the necessary resource mobilization for the main canal above the Tara Prasad Bhond. The decisions of the joint committee (as per the necessity) are also communicated to both the executive committees in formal way.

\section{Rules for Conflict Management for Ensuring the Equity/ Fairness}

The water appropriators have developed their own indigenous system of conflict management. In other words, infractions are resolved through both the informal and formal mechanisms. While discussing the indigenous institutional systems of resolving the conflict in the command areas of both the irrigation systems, the analyses have proceeded at three levels: inter-systemic conflict, inter-Mauja conflict, and intra-Mauja conflict.

Given the fact Sora and Chhattis Mauja irrigation systems have been using the irrigation from the same source of water and from the same mega-canal, sometimes conflicts may occur apropos of the water allocation and distribution and resource mobilization. Under such condition, the joint management governance structure/ committee helps to resolve any outstanding issues/problems between the two systems. Both the systems have been managing the water as a 'commons' very successfully for sustaining their livelihood by resolving inter-systemic conflict through consensus -a function of the mutual discussion, negotiation, trust, solidarity, etc.

Conflicts between and among the Maujas are also the common sociological phenomena in this irrigation system. The conflicts between the head, middle and tail locations arising from the violation of the distributional norms do occur frequently. Some of the conflicts are specific to the cropping seasons. For example, conflicts between the Maujas occur more frequently during the period of the paddy nursery seedbed preparation. Such cases are generally mediated by the system level executive committee. The conflicting parties generally accept the decisions. More specifically, a water monitoring committee comprising of four members has been formed for the settlement of water cases in Sora Mauja irrigation system. This committee charges fine if a Mauja steals the 
water in the turn of another Mauja. It charges Rs. 500 for the one time water theft. All inter-Mauja conflicts are settled within the Maujas. They do not resort to the courts/police/administration for the conflict settlements.

Intra-Mauja conflict is also very frequently occurring sociological phenomenon. The principal sources of the conflict comprise the violation of water distributional turn between head, middle and tail locations, water theft, unjust distribution of water between head, middle and tail farmers (which is disproportionate to the size of the landholding of a particular location), etc. Water theft within the Mauja is more frequent during the period of paddy nursery bed preparation and maize cultivation. Characterizing the scale of the water theft during the period of the maize cultivation in MarchApril, one key informant of Sora- Mauja remarked: "Water appropriators here have a proclivity to steal water very frequently during the period of maize cultivation but they are ready to pay Rs.500 as fine because that payment of fine contributes to accrue Rs. 7000-8000 from the sale of the cobs of maize". When the conflict arises between and among the farmers of the head, middle and tail locations or between and among the water appropriators of a particular location, the issue is brought to the Mauja Muktiyar by the affected party/ies who then make the immediate on the spot observation for the study of the situation. During the period of the observation, the conflicting parties are allowed to present their arguments. The witnesses are also called. Once the complaints of the conflicting parties and the opinions of the witnesses are heard, the Muktiyar tries to persuade the conflicting parties and resolve the issue through compromise. Failing this, the case is brought to the Mauja level mass meeting, which then finalizes the case through the elaborate discussion. The person/s responsible for the infraction of the irrigation norm has/have to accept the decisions of mass arbitration including the compromise/payment of the compensa- tions to the affected party/ies. Generally, the intra-Mauja conflicts are not referred to the police, court and administration. This shows that community verdict is the final one.

Both the irrigation systems have crafted a norm to impose the graduated sanctions on the persons/ Maujas responsible for the infraction of the rules. In the case of Sora Mauja, if any Mauja within the system develops a Mohodha (diversion of the watercourse) from the main canal at its own disposal by severely affecting other Maujas and steals water, Rs.500 is collected as the compensatory fine from this Mauja for the first Kulahai year Rs. 1000 for the second time, Rs. 2000 for the third time and if the act of non-compliance/stealing continues, a compensatory fine up to Rs. 10,000 can be imposed on it. If the water is stolen by a Mauja during the Maujane Palo (rotational turn of a particular Mauja) of another by diverting water from the main canal and if it is proved, it will be fined Rs. 500 for the first time, Rs. 1000 for the second time, and Rs. 2000 for the third time.

Sora Mauja has also the system of imposing the fines for the noncompliance of the rules for the repair and maintenance of the main system canal. The rule stipulates that while repairing and maintaining the main system canal, the Maujas have to finish the assigned Naj/Nath (measurement of the assigned labor work) at the said/specified time. If the assigned work remains incomplete, they have to pay the fines as compensations for the all Kularas. If the Kularas leave the Kulahai after accepting the Naj/Nap, they are imposed double compensatory fines in the usual Khara fixed. The compensatory fines imposed on the Kularas for being absent in the Kulahai is decided by the Sadharansabha every year.

There are also the cultural norms of imposing the graduated sanctions in the larger command area of Chhattis Mauja. For example, if any Mauja develops a Mohoda (diversion of the 
watercourse) from the main system canal at its own disposal by severely affecting other Mauja and steals water, compensatory fines are imposed by looking at the level of negative impact. For the fist time, it will be fined Rs.1000, Rs. 1500 for the second time, and Rs. 3000 for the third time. And if the trend of non-compliance continues, the maximum punishment can be inflicted upon it by closing the Mohoda from the main system canal for a specific season or for the whole year. This norm is also applicable to the case of violating Maujani Palo (the rotational turn of a Mauja) by any Mauja. But the norms of Mauja are applied in the case of violation of the water rights of water appropriators within the Mauja as decided by the functionaries and staff of the Mauja committee. If any Mauja cannot finish the repairing and maintaining the dry main system level in the specified period of time, it has to pay Rs.250 to the committee as Khara per Kulara prior to accepting another Naj/ Nath. Khara has to be paid for the number of days required for completing the Naj/ Nath. The daily rate of Khara for the absence of the Kulahai for other than the dry main system level canal is decided by the Sadharansabha.

\section{Rules for Maintaining Transparency and Accountability}

The cross-cultural studies on the indigenous resource management systems have demonstrated that they have a high degree of transparency and accountability which, in turn, have contributed to ensuring 'social equity'. Transparency in the organizational and institutional system ensures trust/confidence between and among the members-- a strong social capital/asset for harnessing the social energy of the community of the resource appropriators. The culture of maintaining the sustainability of both the irrigation systems is the direct function of the traditionally "nurtured culture of maintaining the transparency and accountability". The operational rules as well as the constitutional provisions are, in fact, framed democratically.
In other words, even though they are drafted by the committees authorized by the powerful decision- making bodies such as the general meeting and the general assembly, they are finally ratified/approved by these bodies after the protracted discussions and deliberations. And the approved copies of the constitutions, which also have the operational rules, have been distributed to the responsible members, functionaries of the different layers of the committees, and the interested water appropriators. So there is complete transparency of the irrigation operational rules and constitutional provisions at the system level. Occasionally, the same powerful decision-making bodies as per the organizational necessity amend these and the amendment process is also transparent because the amendments are discussed elaborately in these powerful decision-making bodies and approved. These constitutional and operational rules have always underscored the equity considerations as discussed in the preceding sections.

The Mauja level committees also frame their own operational rules without contradicting to the system level rules/constitutional provisions. But in so doing, they also get them approved through the Mauja level mass meeting of the water users. The functionaries and members do implement/enforce only those operational rules that are approved by the mass meeting. So transparency of the operational rules is maintained even at the Mauja level.

As indicated earlier, the primary source of income for both the systems is the Khara which is collected by the system level Meth Muktiyars with the support of Mauja/Gaon Muktiyars. The annual irrigation service fee called Bighatti is also collected in each Mauja in lieu of the Kulahai. This collected money is handed over to the treasurer for the proper book-keeping. And given the fact that both the systems have the culture of having the account audited and presenting to the general assemblies/general meetings for the 
elaborate discussion and questioning, there is full transparency of the whole financial system (also see the resource mobilization section). It is these decision-making bodies, which approve the audited record of income and expenditure. If any functionary misappropriates the funds, the public criticism and the pressure of the executive committee are so strong that there is no other way other than returning the misappropriated fund. This transparency encourages the water appropriators to be organized for the mutually beneficial collective action

Given the fact that the command areas of both the irrigation systems are increasingly being urbanized, there is already high level of awareness among the water appropriators apropos of the roles of the irrigation functionaries and the staff of the system level and Mauja/Gaon level committees. The awareness is triggered by the literacy/education variable. Succinctly put, all of the functionaries/ leaders including the staffs have to be accountable to the water appropriators. If they cannot work for the promotion of the collective interest/ equitable distribution of the benefits, there can be growing complaints by the water appropriators against them.

Once the issue of the injustice or deprivation of the benefits begins surfacing, fellow water appropriators also take such incidence very seriously and there is the talk in the community about it. Though party politics is not played within the organization after the election, the political groupings can play an important role in determining and electing the functionaries and the members of the nested enterprise. Hence, the issues of the unaccountability and injustice can be capitalized during the time of the election and the functionaries/members may not be elected/selected again. Therefore, the degree of accountability is high in both the systems. It is also the same for the system level and Mauja level staff. For example, it has also been ascertained that both the system level
Meth Muktiyars and Mauja/Gaon level Muktiyars are also required to be transparent and accountable in executing the decisions. Failure to do so may result in the severe "public criticism". Dismissal may be the eventual outcome.

\section{Closing Remarks}

The traditional farmer-managed irrigation systems have succeeded in addressing social issues such as equity among the water appropriators. In other words, there is always an effort for putting people first in such systems and therefore, they have been sustainable for relatively long period of time. When there had been no focus on the people and other social issues under the modernization paradigm and over-emphasis on the rational technology in 1950s and 1960s, the development interventions including in the irrigation sector could not be sustainable. It followed as a corollary that a group of social scientists, mainly sociologists and social anthropologists, began emphasizing on "putting people first" in development projects in 1980s. Michael Cernea (1985) considers "putting people first" as a firm request to give priority to what is the basic factor in development. In fact, he considers the vital role of sociology and social anthropology as the non-economic social sciences, which study peoples, cultures, and societies. These are slowly being recognized because of the repeated failures in development programs which were sociologically ill-informed and ill- conceived. This reluctant recognition leads to increased interest in identifying and addressing the sociocultural variables of projects. Rules for Maintaining Social Equity among the Disadvantaged Groups within the Irrigation Systems.

In fact "putting people" under the contemporary people-centered development paradigm means emphasizing on social issues such as equity consideration and a lot of lessons can be learned in this 
regard from the traditional farmer-managed irrigation systems such as the ones described in this paper.

Given the fact that irrigation management is a mutually beneficial collective action, there is the involvement of multi-stakeholders in the systems studied. These farmers have a democratic space to participate in the decision-making process and articulate their interests. As noted in this paper, smaller holders and autochthonous Tharus are the disadvantaged groups. Most of these social groups have direct participation in the meetings/ general assemblies of the Mauja (village) level committee. In these fora, every member of these social groupings is encouraged by the local leadership to articulate their opinions/ voices, share their irrigation- related problems, assess the performances of the leadership and policies, and their inconsistencies (if any). In the system level governance structures also, the voices of the different interest groups have been heard because the leaders represent them.

As analyzed in the preceding sections, both the systems have evolved the norm for the equitable distribution of the water, that is, every appropriator is entitled to receive the water proportionate to the size of the landholding, which is again determined, by the amount of contribution (cash or labor or both) as per the necessity. This fair distribution of water as per the norm is equally applicable to all the water appropriators regardless of the socio-economic statuses. This means the minority Tharu ethnic people as well as the small holders have also the right to the equitable distribution of water. There is no evidence of the discrimination in this regard. The activities of the governance-nested enterprises such as the resource mobilization, conflict management, communication, etc basically contribute to ensuring social equity among water appropriators of both irrigation systems. Therefore, it can be safely concluded that farmer-managed irrigation systems have been sustainable for a relatively long period of time because the water appropriators have a perception that: they have been fairly represented in the governance structures/decision-making processes; that they have been asked to make equitable contribution to repair and maintain the systems on which their livelihood depends, and that they have enjoyed the fair distribution of irrigation benefits.

\section{End notes}

I am grateful to Dr. Ram B. Chhetri, the Chairman of the Central Department of Sociology and Anthropology, Tribhuvan University, for encouraging me to write this paper. I acknowledge Mr. Keshav Neupane, the ex-chairman of the executive committee of Chhattis Mauja and the current chairman of the National Federation of the Water Users' Association of Nepal, Mr Rukmakher Pandey, the current chairman of Chhattis Mauja system level executive committee, Mr. Dadhi Ram Gautam, Meth Muktiyar of Chhattis Mauja, Mr. Sukdev Neupane, the chairman of the executive committee of Sora Mauja and Mr. Dev Bahadur Gurung, the Meth Muktiyar of Sora Mauja for their commendable support to conduct the fieldwork for this paper. Lastly, I also acknowledge Mr. Sarad Simkhada, the Lecturer of Anthropology/Sociology at Drabya Shah Campuus, Gorkha for his professional help in garnering in the necessary empirical data.

Bigha $=0.6772$ hectares

Bighatti $=$ annual irrigation service fee per Bigha

Bhujabhandi= labor contribution with tiffin to work for the full day until the repair and maintenance of the main canal system and headwork is over

Chauble $=$ four laborers to be sent per 25 Bighas of land

Chaukidar $=$ watchman-cum-messenger in the local context

Doule $=$ two laborers to be sent per 25 Bighas of land

Gaon= village

Kattha $=0.0339$ hectares 
Khara $=$ fine imposed on absentee water appropriator

Kulara $=$ one Kulara means one laborer per 25 Bighas of land which is the unit of water allocation between and among the Muajas of the irrigation systems

Jharuwa $=$ contribution of labor for the repair and maintenance of the canal system on compulsory basis by each water appropriating household until the work is over

Mauja $=$ a settlement cluster which roughly corresponds to a village

Maujani Nath/Nap= the measurement of the main canals assigned by the Meth Muktiyar to each Mauja for the annual repair and maintenance which is proportionate to the size of its command area

Meth Muktiyar=-the chief system level staff

Sabik $=$ as usual, for instance, one laborer to be sent per 25 Bighas of land

Sheer Kualhai= labor work for the repair and maintenance of the headwork of the canal

Sidhabandhi= labor contribution with foodstuff for the night halt until the repair and maintenance of the main canal system and headwork is over

Treble $=$ three laborers to be sent per 25 Bighas of land

\section{References Cited}

Berkes, F. and M.T. Farvar, 1989. "Introduction and Overview in F. Berkes" pp. 1-17, Common Property Resources: Ecology and Community - Based Sustainable Development. London; Belhaven Press,

Bennett, J.W.1996. Human Behaviour: Essays in Environment and Development Anthroplology. London: Transaction Publishers, UK.

Carol, P.C.; Byron, Y; Prabhu, Ravi and Wollenberg, E. "Introduction: History and Conceptual Framework" in Carol, P.C.; Byron, Y.2001. People Managing Forests. Washington, DC: Resource for the Future, U.S.A and Bogor: Centre for International Forestry Research, Indonesia.
Cernea, Michael.1995." Sociological Knowledge for Development Projects" in Michael Cernea (ed.) Putting People First: Sociological Variables in Rural Developmet,Published for the World Bank, Washington: Oxford University Press.

Coward, E. Walter, Jr. 2004. Property and FMIS Governance: Two Books That May Be Unfamiliar, But That Inform The Discussion. A Keynote Speech Delivered in the Third International Seminar on "Farmer-Managed Irrigation Systems and Governance Alternatives" on 9-10 September, 2004, Kathmandu, Nepal.

Coward, E. Walter, Jr. 1985."Technical and Social Change in Currently Irrigated Regions: Rules, Roles, and Rehabilitation" in Michael Cernea (ed.) Putting People First: Sociological Variables in Rural Development. Published for the World Bank, Washington: Oxford University Press.

Coward. E. Walter, Jr. 1986. "State in Locality in Asian Irrigation Development: in K.C Nobe and R.K Sampath (ed.) The Property Factor" Irrigation Management in Developing Countries: Current Issues and Approaches.Boulder: Westview Press.

Coward, E. Walter, Jr. 1979. Principles of Social Organization in an Indigenous Organization, Human Organization, vol.38,pp .28-36

Fisher, R.J.1991. Studying Indigenous Forest Management Systems in Nepal: Toward a More Systematic Approach. Honolulu: Environment and Policy Institute, East- West Center, USA.

Gautam, Upendra and Uprety, Laya Prasad.2002.Distributive Justice in the Development of Water Resources: Experience and Option from Nepal. A Paper Presented for the First South Asia Water Forum Held in Kathmandu, Nepal from 26 to 28 February,, 2002.

Ghate, Ruche.2003. Ensuring Collective Action in Participatory Forest Management. Working Paper No.-3-03, South Asian Network for Development and Environmental Economics. Kathmandu, Nepal.

Gilmour, D.A and Fisher, R.J.1992. Villagers, Forests and Foresters. Kathmandu: Sahyogi Press, Nepal. 
Jodha.N.S.1994. "Common Property Resources and the Rural Poo" in Ramchandra Guha (ed.) Social Ecology. New Delhi: Oxford University Press, India.

Lind, E. Allan.1995. Social Conflict and Social Justice: Lessons from the Social Psychology of Justice Judgments. Leiden: Leiden University, The Netherlands.

Korten, F.1982. Building National Capacity to Develop Water Users' Group Association: Experience from the Philippines. A World Bank Staff Working Paper. No. 528. Agricultural and Rural Development Department, Washington, D.C: The World Bank

Korten, David.1990. Getting to the $21^{\text {st }}$ Century. New Delhi. Oxford and IBH publishing Co. PVT. LTD, India.

Martin, E.D. 1986. Resource Mobilization, Water Allocation and Farmer Organization in the Hill Irrigation System in Nepal. Ph.D. Dissertation Presented to the Faculty of Graduate School of Cornell University, New York: U.S.A

Mukherjee,N. 2002. Forest Protection Committee of West Bengal: Measuring Social Capital in Joint Forest Management. New Delhi, India.

Ostrom, E. 1997. Self-Governance and Forest Resources", Conference on 'Local Institutions for Forest Management: How Can Research Make Difference? CIFOR, Bogor, Indonesia, November 19-21. http://www.cgiar.org/for.

Ostrom, Elinor.1996. Governing the Commons: The Evolution of Institutions for Collective Actions. New York: Cambridge University Press.

Ostrom, Elinor. 1992. Crafting Institutions: Self-governing Irrigation Systems. California: Institute for Contemporary Studies, U.S.A.

Place, F. and Shallow, B, 2000. Assessing the Relationships Between Property Rights and Technology in Smallholder Agriculture: A Review of Issues and Empirical Methods. Washington, D.C: International Food Policy Research Institute, U.S.A.
Pradhan, Prachanda. 1989. Patterns of Irrigation Organization in Nepal. Colombo: International Irrigation Management Institute, Sri lanka.

Shukla ,Ashutosh and Sharma, Khem Raj.1997. Participatory Irrigation Management in Nepal. Kathmandu: Printers Universe (P.) Ltd, Nepal.

Slater, Rachel and Twyman, Chasca, 2003. Hidden Livelihood? Natural Resource- Dependent Livelihoods and Urban Development Policy. A Working Paper, London: Overseas Development Institute, 111 Westminister Bridge Road, SEI, 7JD, UK.

Tang, Shui Yan. 1989. Institutions and Collective Action in Irrigation Systems. Ph.D Dissertation Submitted to the Faculty of the Graduate School in Partial Fulfilment of the Requirements in Public Policy, Indiana University, USA.

Uphoff, Norman.1996. Learning from Gal Oya: Possibilities for Participatory Development and Post-Newtonian Social Science. London: IT Publications.

Uprety, Laya Prasad. 2002. Literature Review on Managing Water for Irrigation as a Common Property Resource. An Academic Report Submitted to the Dean's Office of the Institute of Humanities and Social Sciences, Tribhuvan University for the Fulfillment of the Partial Requirement for Ph.D in Anthropology, Kitipur, Kathmandu.

Uprety, Laya Prasad. 2004. Aspects of Social Capital and their Roles in the Sustainability of Irrigation Management: A Case Study of Sora- Chhattis Mauja Farmer-managed Irrigation Systems from the Western Terai, Nepal. A Paper Presented at the Third international Seminar on "Farmer-managed Irrigation Systems and Governance Alternatives" Organized by the Farmermanaged Irrigation Systems Promotion (FMIS) Trust Held in Kathmandu on 9-10 September, 2004. 